\title{
Editorial
}

\section{O papel das revisões de literatura na produção e síntese do conhecimento científico em Psicologia}

\author{
Mário César Rezende Andrade \\ Editor executivo
}

Os estudos de revisão de literatura estão entre as fontes bibliográficas mais relevantes para a construção e divulgação do conhecimento científico. Ao identificar e sintetizar as principais contribuições à literatura sobre determinado tópico, esse tipo de publicação fornece aos leitores um verdadeiro relatório sobre o estado da arte ou sobre os avanços em seu campo de conhecimento (Maggio, Sewel \& Artino Jr., 2016; Ribeiro, 2014). As revisões fornecem, também, uma longa lista de referências, as quais embasam tal síntese e podem ser consultadas pelos pesquisadores da área (Figueiredo, 1990). Além disso, os estudos de revisão podem facilitar o trabalho científico de forma significativa, como, por exemplo, auxiliando os pesquisadores na formulação de um problema de pesquisa, na discussão dos seus achados, ou até mesmo apontando lacunas a serem preenchidas, contribuindo, consequentemente, com o avanço do conhecimento. Tal relevância das revisões de literatura se faz presente em todas as áreas, inclusive, na Psicologia.

De acordo com Figueiredo (1990), os artigos de revisão possuem dois papeis específicos, que estão relacionados entre si. O primeiro seria a sua função histórica, considerando que as revisões se constituem como parte do próprio desenvolvimento científico. Essa função ocorre à medida que as revisões oferecem uma visão geral do estado de desenvolvimento de um assunto em determinado período. A outra função seria a de atualização, que ocorre por meio da compilação das informações correntes a partir das principais fontes da literatura de uma área de conhecimento, orientando o ensino e a formulação de novas pesquisas. Esse papel dos estudos de revisão se torna cada vez mais necessário no mundo contemporâneo, principalmente a partir do último século, considerando a grande quantidade e fluxo de informações (Moreira, 2004; Soares et al., 2013). 
Com relação à categorização das revisões, existem diversas propostas de tipologia, que variam de acordo com seu objetivo e seu conteúdo (Grant $\&$ Booth, 2009; De Sousa et al., 2018). Entretanto, para fins didáticos e refletindo a maior parte dos artigos de revisão submetidos à Gerais: Revista Interinstitucional de Psicologia, como também a outros periódicos brasileiros, cabe destacar três tipos principais: as Revisões Sistemáticas, Integrativas e Narrativas (Casarin et al., 2020; Soares et al., 2013).

A Revisão Sistemática consiste em um tipo planejado e estruturado de estudo, que tem como objetivo sintetizar as evidências produzidas por estudos primários acerca de uma determinada questão específica, explicitando os critérios de busca, de exclusão e retenção de artigos. Nesse tipo de revisão, é apresentada uma lista completa dos estudos identificados, com suas características e resultados, além de uma análise de sua qualidade metodológica. As Revisões Sistemáticas podem incluir, quando possível, uma síntese quantitativa dos resultados, combinando os dados dos estudos revisados, conhecida como Metanálise. As Revisões Sistemáticas com Metanálise estão incluídas no topo da pirâmide de estudos que fornecem maior base de evidências científicas sobre determinado assunto (Cordeiro, Oliveira \& Rentería, 2007; De-la-Torre-Ugarte-Guanilo, Takahashi \& Bertolozzi, 2011 ; Sampaio \& Mancini, 2007).

A Revisão Integrativa, por sua vez, é também uma pesquisa planejada, com critérios explícitos e sistemáticos para buscar e selecionar os estudos a serem sintetizados. Entretanto, esse tipo de revisão busca responder a uma questão de pesquisa mais ampla, em comparação com a Revisão Sistemática. Além disso, permite incluir diferentes tipos de estudo, quantitativos, qualitativos e até mesmo teóricos. As Revisões Integrativas também fornecem informações mais amplas dos artigos sintetizados, podendo incluir dados teóricos, metodológicos ou empíricos. (Ercole, Melo \& Alcoforado, 2014; Souza, Silva \& Carvalho, 2010).

Por fim, a Revisão Narrativa se diferencia das outras duas modalidades de revisão, focando apenas em mapear o conhecimento produzido em determinada área, sem critérios sistemáticos para busca, retenção de artigos e extração de informações (Cordeiro et al., 2007; Rother, 2007; Soares et al., 2013). Apesar de ser um tipo de revisão muito comum, muitos periódicos, incluindo a Gerais, a partir deste ano, tem deixado de publicar Revisões 
Narrativas, devido ao seu menor rigor e à falta de critérios explícitos. Por outro lado, devese destacar o papel relevante das Revisões Narrativas nas seções de revisão de literatura das teses e dissertações, como um mapa geral do conhecimento produzido em determinada temática.

A presente edição da Gerais (v14nS) consiste em um número especial constituído apenas por artigos de revisão de literatura. Os 12 artigos que compõem esta edição estão distribuídos entre as três tipologias apresentadas. O processamento editorial deste número da revista se tornou possível graças ao apoio do Departamento de Psicologia da UFSJ, por meio do suporte financeiro para "Contratação de prestação de serviços não contínuos" (processo número 23122.019742/2020-80), e do edital 05/2017, da Fundação de Amparo à Pesquisa do Estado de Minas Gerais (FAPEMIG), pelo "Programa de apoio a publicações científicas e tecnológicas, publicação de periódicos institucionais".

Além disso, aproveitamos a oportunidade do presente editorial para informar a adoção, neste ano, de novas normas e instruções para submissão de artigos à Gerais, disponíveis no site do periódico. Tais mudanças incluem, entre outras, a inclusão de um novo modelo de carta de submissão, um template para a escrita do artigo a ser submetido e um checklist a ser preenchido e assinado pelo autor responsável. Esse checklist varia de acordo com o tipo de estudo a ser submetido, o que inclui: Relatos de Pesquisa, com metodologias quantitativas e qualitativas; Ensaios; Revisões de Literatura; e Relatos de Experiência. Essas mudanças foram realizadas visando a facilitação e melhoria da qualidade do processamento editorial dos artigos submetidos.

\section{Referências}

Casarin, S. T., Porto, A. R., Gabatz, R. I. B., Bonow, C. A., Ribeiro, J. P., \& Mota, M. S. (2020). Tipos de revisão de literatura: considerações das editoras do Journal of Nursing and Health. Journal of Nursing and Health, 10(5), e20104031. https://doi.org/10.15210/JONAH.V10I5.19924 
Cordeiro, A. M., Oliveira, G. M. D., Rentería, J. M., \& Guimarães, C. A. (2007). Revisão sistemática: uma revisão narrativa. Revista do Colégio Brasileiro de Cirurgiões, 34, 428-431.

De-la-Torre-Ugarte, M. C., Takahashi, R. F., \& Bertolozzi, M. R. (2011). Revisão sistemática: noções gerais. Revista da Escola de Enfermagem da USP, 45(5), 1260-1266.

De Sousa, L. M. M., Firmino, C. F., Marques-Vieira, C. M. A., Severino, S. S. P., \& Pestana, H. C. F. C. (2018). Revisões da literatura científica: tipos, métodos e aplicações em enfermagem. Revista Portuguesa de Enfermagem de Reabilitação, 1(1), 45-54. https://doi.org/10.33194/rper.2018.v1.n1.07.4391

Ercole, F. F., Melo, L. S. D., \& Alcoforado, C. L. G. C. (2014). Revisão integrativa versus revisão sistemática. Revista Mineira de Enfermagem, 18(1), 9-12. http://www.dx.doi.org/10.5935/1415-2762.20140001

Figueiredo, N. (1990). Da importância dos artigos de revisão da literatura. Revista Brasileira de Biblioteconomia e Documentação, 23(1/4), 131-135.

Grant, M. J., \& Booth, A. (2009). A typology of reviews: an analysis of 14 review types and associated methodologies. Health information \& libraries journal, 26(2), 91-108.

Moreira, W. (2004). Revisão de literatura e desenvolvimento científico: conceitos e estratégias para confecção. Janus, 1(1), 21-30.

Maggio, L. A., Sewell, J. L., \& Artino Jr, A. R. (2016). The literature review: A foundation for high-quality medical education research. Journal of graduate medical education, 8(3), 297-303. https://doi.org/10.4300/JGME-D-16-00175.1

Ribeiro, J. L. P. (2014). Revisão de investigação e evidência científica. Psicologia, Saúde e Doenças, 15(3), 672-683. http://dx.doi.org/10.15309/14psd150309

Rother, E. T. (2007). Revisão Sistemática X revisão narrativa. Acta Paulista de Enfermagem, 20(2), 5-6. https://doi.org/10.1590/S0103-21002007000200001

Sampaio, R. F., \& Mancini, M. C. (2007). Estudos de revisão sistemática: um guia para síntese criteriosa da evidência científica. Brazilian Journal of Physical Therapy, 11, 83-89. https://doi.org/10.1590/S1413-35552007000100013 
Soares, L. S., Rodrigues, I. D. C. V., Martins, L. N., Silveira, F. D. R., \& Figueiredo, M. L. F. (2013). Revisão de literatura: particularidades de cada tipo de estudo. Revista de Enfermagem da UFPI, 2, 14-8.

Souza, M. T. D., Silva, M. D. D., \& Carvalho, R. D. (2010). Revisão integrativa: o que é e como fazer. Einstein (São Paulo), 8, 102-106. https://doi.org/10.1590/S1679$\underline{45082010 R W 1134}$ 